\title{
Micronutrient intake in relation to all- cause mortality in a prospective Danish cohort
}

\author{
Nina Roswall'*, Anja Olsen', Jane Christensen', \\ Louise Hansen', Lars O. Dragsted ${ }^{2}$, Kim Overvad ${ }^{3}$ and \\ Anne Tjønneland'
}

\author{
'Institute of Cancer Epidemiology, Danish Cancer Society, Copenhagen, Denmark; ${ }^{2}$ Faculty of Life Sciences, \\ Department of Human Nutrition, University of Copenhagen, Copenhagen, Denmark; ${ }^{3}$ Department of Clinical \\ Epidemiology, Aarhus University Hospital, Aalborg, Denmark
}

Abstract

Background: Few studies have considered source-specific micronutrient intake in relation to mortality under the consideration that dietary and supplemental intake could exhibit different effects.

Objective: To evaluate the association between intake of vitamin C, E, folate, beta-carotene from diet and supplements, and overall mortality. Furthermore, to examine effect modification by smoking, alcohol intake, and BMI and to investigate if the effect of supplement use differs with dietary micronutrient intake.

Methods and Material: In a prospective cohort study of 55,453 middle-aged Danes, information regarding diet, supplement use, and lifestyle was collected through questionnaires. During follow-up, 6,767 deaths were identified and incidence rate ratios (IRRs) of mortality related to micronutrient intake were calculated using Cox proportional hazards models.

Results: The present study found no effect of dietary vitamin C, E, folate, or beta-carotene in relation to mortality. In contrast, supplemental folic acid was associated with a significantly increased mortality, whereas no other micronutrient supplement was associated with mortality. Effect modification by smoking and alcohol intake, but not BMI, was suggested in relation to some dietary micronutrients. The effect of supplements did not differ in groups defined by dietary micronutrient intake.

Conclusion: This study suggests no effect of dietary micronutrients in relation to overall mortality. Supplemental folic acid was found to be associated with increased mortality, but further studies are required. No other supplemental micronutrient was associated with mortality.

Keywords: mortality; dietary supplements; micronutrients; prospective cohort study; vitamin $C$; vitamin E; folate; beta-carotene

$\mathrm{O}$ xidative stress has been suggested to play a role in the development of cancer $(1,2)$ as well as cardiovascular disease (3), the two leading causes of death in industrialised countries. On the basis of this, it has been proposed that antioxidants might decrease the risk of these diseases and hereby overall mortality.

Antioxidants and other micronutrients are frequent in the diet, especially in fruit and vegetables, but are also commonly consumed through supplements. Whereas some studies report that dietary micronutrient intake is associated with beneficial effects in relation to cancer (4) and cardiovascular disease $(5,6)$, studies on supplemental micronutrients have fairly consistently shown no bene- ficial effects, and some studies have even suggested harmful effects of micronutrient supplements in relation to mortality $(7,8)$ and to specific cancer and cardiovascular disease outcomes (9-13).

In Denmark, use of micronutrient supplements is widespread with more than $50 \%$ of the population using supplements regularly (14). This is the highest frequency of use in Europe $(14,15)$, but use is generally common in the northern parts of Europe (14) and in the United States (16). For some micronutrients, a supplement becomes the primary source of the micronutrient among users (17), as supplemental micronutrients are often more bioavailable than their natural counterparts (17-20). 
It has been speculated that micronutrients have different effects when consumed through the diet compared to when consumed in a supplement due to differences in dose $(18,21,22)$, but also that the micronutrient source in itself may render different effects of the same micronutrient due to different biological properties $(23,24)$ and synergistic interactions of dietary micronutrients and other parts of the food matrix, which cannot be replicated in supplements (25-27). Few studies have specifically considered source-specific effects of micronutrients in relation to mortality under the consideration that these could differ.

On the basis of this, the aim of the present study was to evaluate the association between intake of dietary and supplemental vitamin $\mathrm{C}$, vitamin $\mathrm{E}$, folate, beta-carotene, and overall mortality. Furthermore, we examined effect modification by smoking, alcohol intake, BMI, and if the effect of supplement use differed in groups defined by dietary micronutrient intake.

\section{Material and methods}

\section{Study cohort}

The prospective Diet, Cancer and Health study invited 160,725 Danes to participate from 1993 to 1997. Inclusion criteria were 50-64 years of age, residence in the greater Copenhagen or Aarhus area, and no previous cancer diagnosis in the Danish Cancer Registry; 57,053 participants accepted the invitation (28). The study was approved by the regional ethical committees of human studies in Copenhagen and Aarhus and by the Danish Data Protection Agency.

\section{Diet and risk factor assessment}

Diet was assessed at baseline through a 192-item food frequency questionnaire (29) considering food intake and supplement use during the past 12 months. Description of the development and validation of the questionnaire has been published previously (29-32). Average intake of each food item during the last 12 months was reported in 12 possible categories from 'never' to 'eight times or more per day.' Participants also provided information on supplement use through open-ended questions on brands and doses and categorical questions on consumption frequency; that is, how many months during the last year they had consumed the supplements and how many tablets they had consumed per day in the given period. Information on micronutrient content in each supplement brand was obtained from producers or distributors. For each participant, average daily micronutrient intake was calculated by the software programme Food Calc (33) as total, dietary, and supplemental intake. Furthermore, each participant filled in a lifestyle questionnaire including information on factors relevant for mortality.

\section{Exclusion criteria}

Participants were excluded if they lacked information concerning micronutrient intake or covariates $(n=$ $1,600)$. In total, 26,609 men and 28,844 women were included in the analyses.

\section{Follow-up and case ascertainment}

Information on vital status and emigration of participants was obtained from the Central Population Registry. Follow-up was initiated on the day of the visit to the study clinic and continued until date of death, date of emigration, or March 30, 2010 - whichever came first.

\section{Statistical analysis}

The analyses between exposure variables and mortality were based on Cox proportional hazards models with follow-up time as the underlying time scale. We stratified for age in 1-year intervals; that is, allowing for different shapes of the hazard function in the different age intervals (34).

Estimates were calculated as crude estimates and as adjusted estimates. All adjusted models were adjusted for alcohol intake (g/day), Body Mass Index (BMI) $\left(\mathrm{kg} / \mathrm{m}^{2}\right)$, waist circumference $(\mathrm{cm})$, smoking status (never, former, current), smoking duration (years), smoking intensity (g/ day), time since cessation (years), educational status $(<7$, $7-10,>10$ years), physical activity (sport [yes/no] and cycling [yes/no]). Supplemental and dietary intake was always mutually adjusted and when considering one micronutrient, the analyses were adjusted for the three others.

Quantitative variables were included linearly in the Cox model as this increases the power of the analysis (35). Linearity was evaluated graphically using linear spline models with boundaries at the three quartiles among cases (36). Both BMI and alcohol intake were found to be related to mortality in a U-shaped association and were therefore each entered into the models as linear splines with boundaries placed at BMI: $25 \mathrm{~kg} / \mathrm{m}^{2}$ and alcohol intake: $10 \mathrm{~g} / \mathrm{day}$ for both sexes. No other variables showed deviation from linearity, and these were therefore included linearly into the model.

Incidence rate ratios (IRRs) of the association with linear micronutrient variables were presented as IRRs associated with a $100 \mathrm{mg} / \mathrm{day}$ higher consumption for vitamin $\mathrm{C}, 10 \mathrm{mg} / \mathrm{day}$ for vitamin $\mathrm{E}, 100 \mu \mathrm{g} / \mathrm{day}$ for folate, and $5,000 \mu \mathrm{g} /$ day for beta-carotene. These units were based on evaluations of the interquartile range of the different linear micronutrient variables among cases.

All tests were based on the likelihood ratio test statistic. Two-sided 95\% confidence intervals were calculated based on Wald's test of the Cox regression parameter, i.e. on the log ratio scale. The SAS procedure PHREG in SAS 8.2 on the TextPad platform was used for statistical analyses. 


\section{Results}

A total of 6,767 deaths occurred during a median followup of 13.8 years (5-95\% percentile: 7.6-15.4). The characteristics of the study population are summarised in Table 1. As expected, cases were older at baseline and a higher number were males, current smokers, had a lower education, and a higher daily alcohol intake (Table 1).

Table 2 shows the relationship between micronutrient intake and mortality. We found a significantly increased mortality risk with supplemental folic acid (IRR: 1.02, 95\% CI: 1.01-1.03) but not with dietary folate (IRR: 1.02 , 95\% CI: 0.98-1.05). When considering total folate, the association was also significant (IRR: 1.02 , 95\% CI: 1.01 1.03). No other micronutrient was associated with mortality regardless of source: diet, supplement, or total intake (results not shown).

To consider possible effect modification by lifestyle, analyses were conducted stratified by smoking status

Table 1. Baseline characteristics of cases and study-population by selected demographic and established risk factors and intake of micronutrients

\begin{tabular}{|c|c|c|c|c|c|c|}
\hline \multicolumn{3}{|c|}{ Cases $(n=6,767)$} & \multicolumn{3}{|c|}{ Cohort $(n=55,453)$} & \multirow[b]{2}{*}{$N(\%)$} \\
\hline Median & & 5-95\% percentile & $N(\%)$ & Median & $5-95 \%$ & \\
\hline Age at baseline & 59.0 & $51.0-64.0$ & & 56.0 & $50.0-64.0$ & \\
\hline \multicolumn{7}{|l|}{ Sex } \\
\hline Male & & & $4073(60.2)$ & & & $26609(48.0)$ \\
\hline Female & & & $2694(39.8)$ & & & $28844(52.0)$ \\
\hline \multicolumn{7}{|l|}{ Smoking status } \\
\hline Never & & & $1223(18.1)$ & & & $19573(35.3)$ \\
\hline Former & & & $1630(24.1)$ & & & $15733(28.4)$ \\
\hline Current & & & $3914(57.8)$ & & & $20147(36.3)$ \\
\hline BMI $\left(\mathrm{kg} / \mathrm{m}^{2}\right)$ & 26.0 & $19.9-34.9$ & & 25.6 & $20.5-33.4$ & \\
\hline \multicolumn{7}{|l|}{ Education } \\
\hline$<7$ years & & & $2886(42.7)$ & & & $18365(33.1)$ \\
\hline $7-10$ years & & & $2807(41.5)$ & & & $25513(46.0)$ \\
\hline$>10$ years & & & $1074(15.9)$ & & & 11575 (20.9) \\
\hline Alcohol intake (g/day) ${ }^{4}$ & 15.7 & 1.089 .2 & & 13.4 & $1.1-65.1$ & \\
\hline Sport & & & $2589(38.3)$ & & & $29653(53.5)$ \\
\hline Cycling & & & $3949(58.4)$ & & & $37428(67.5)$ \\
\hline \multicolumn{7}{|l|}{ Vitamin C (mg/day) } \\
\hline Dietary intake & 91.8 & $38.0-213.6$ & & 97.8 & $44.1-210.2$ & \\
\hline Supplemental intake ${ }^{5}$ & 60.0 & $7.1-666.0$ & & 60.0 & $7.1-590.0$ & \\
\hline Percentage using supplements & & & $3193(47.2)$ & & & $28563(5 \mid .5)$ \\
\hline \multicolumn{7}{|l|}{ Folate $(\mu \mathrm{g} /$ day $)$} \\
\hline Dietary intake & 318.8 & | $78.7-542.3$ & & 325.2 & $|89.4-52| .8$ & \\
\hline Supplemental intake ${ }^{5}$ & 100.0 & $16.7-300.0$ & & 100.0 & $11.9-283.2$ & \\
\hline Percentage using supplements & & & $2620(38.7)$ & & & $23418(42.2)$ \\
\hline \multicolumn{7}{|l|}{ Vitamin E (mg/day) } \\
\hline Dietary intake & 8.3 & $4.4-14.8$ & & 8.6 & $4.7-\mid 4.3$ & \\
\hline Supplemental intake ${ }^{5}$ & 10.0 & $1.4-72.0$ & & 10.0 & $1.2-75.0$ & \\
\hline Percentage using supplements & & & $300 I(44.1)$ & & & $27417(49.4)$ \\
\hline \multicolumn{7}{|l|}{ Beta-carotene $(\mu \mathrm{g} /$ day $)$} \\
\hline Dietary intake & 2480.9 & $603.1-11769.8$ & & 3205.4 & $795.9-13016.3$ & \\
\hline Supplemental intake ${ }^{5}$ & 2254.5 & $187.2-15300.0$ & & 2254.5 & $187.2-16002.5$ & \\
\hline Percentage using supplements & & & $120(1.8)$ & & & $1435(2.6)$ \\
\hline
\end{tabular}

\footnotetext{
I Among ever smokers.

${ }^{2}$ Among current smokers.

${ }^{3}$ Among former smokers.

${ }^{4}$ Among drinkers.

${ }^{5}$ Among users.
} 
Table 2. Incidence rate ratios (IRR) for all-cause mortality associated with intake of vitamin C, folate, vitamin E, and beta-carotene

\begin{tabular}{|c|c|c|c|c|c|c|c|}
\hline & \multicolumn{4}{|c|}{ Continuous analyses } & \multicolumn{3}{|c|}{ Categorical analyses $^{2}$} \\
\hline & Crude IRR' $95 \% \mathrm{Cl}$ & $\begin{array}{c}\text { Adjusted IRR }{ }^{1.2} 95 \% \\
\mathrm{Cl}\end{array}$ & $\begin{array}{c}\text { Group I } \\
\text { (low) }\end{array}$ & Group 2 & Group 3 & Group 4 (high) & $\begin{array}{c}\text { Test for } \\
\text { trend }\end{array}$ \\
\hline \multicolumn{8}{|l|}{ Vitamin $C^{3}$} \\
\hline Dietary intake & $0.85(0.8 \mathrm{I}-0.90)$ & $1.05(0.99-1.11)$ & 1.0 (ref.) & $0.88(0.82-0.94)$ & $0.87(0.80-0.93)$ & $0.97(0.89-1.06)$ & 0.08 \\
\hline $\begin{array}{l}\text { Supplemental } \\
\text { intake }\end{array}$ & $1.00(0.99-1.00)$ & $1.00(0.99-1.01)$ & I.0 (ref.) & $0.97(0.88-1.07)$ & $1.06(0.95-1.18)$ & $1.02(0.93-I .12)$ & 0.51 \\
\hline \multicolumn{8}{|l|}{ Folate $^{4}$} \\
\hline Dietary intake & $0.94(0.91-0.96)$ & $1.02(0.98-1.05)$ & I.0 (ref.) & $0.88(0.82-0.95)$ & $0.87(0.8 \mathrm{I}-0.94)$ & $0.93(0.85-1.03)$ & 0.38 \\
\hline $\begin{array}{l}\text { Supplemental } \\
\text { intake }\end{array}$ & $1.00(0.99-1.02)$ & $1.02(1.01--1.03)$ & I.0 (ref.) & $1.06(0.96-1.16)$ & $1.13(1.02-1.24)$ & $1.04(0.94-1.16)$ & 0.0025 \\
\hline \multicolumn{8}{|l|}{ Vitamin $E^{5}$} \\
\hline Dietary intake & $0.76(0.70-0.82)$ & $0.90(0.80-1.02)$ & I.0 (ref.) & $0.85(0.80-0.92)$ & $0.81(0.75-0.88)$ & $0.85(0.78-0.94)$ & 0.10 \\
\hline $\begin{array}{l}\text { Supplemental } \\
\text { intake }\end{array}$ & $0.99(0.99-1.00)$ & $1.00(1.00-1.01)$ & I.0 (ref.) & $0.83(0.75-0.92)$ & $0.89(0.80-0.99)$ & $0.88(0.79-0.98)$ & 0.70 \\
\hline \multicolumn{8}{|l|}{ Beta-carotene $^{6}$} \\
\hline Dietary intake & $0.86(0.83-0.89)$ & $0.98(0.95-1.01)$ & 1.0 (ref.) & $0.86(0.80-0.92)$ & $0.8 \mathrm{I}(0.75-0.87)$ & $0.79(0.73-0.86)$ & 0.29 \\
\hline $\begin{array}{l}\text { Supplemental } \\
\text { intake }\end{array}$ & $0.91(0.82-1.01)$ & $1.02(0.91-1.15)$ & I.0 (ref.) & $0.80(0.58-1.09)$ & $0.92(0.68-1.26)$ & $0.87(0.63-1.19)$ & 0.78 \\
\hline
\end{tabular}

\footnotetext{
' Per $100 \mathrm{mg}$ increment/day for vitamin C, $100 \mu \mathrm{g}$ increment/day for folate/folic acid, $10 \mathrm{mg}$ increment/day for vitamin E, and 5,000 $\mu \mathrm{g}$ increment/day for beta-carotene.

${ }^{2}$ Adjusted for total intake of the three other micronutrients as well as dietary intake for the supplemental intake and supplemental intake for the dietary intake and further for alcohol intake, BMI, waist circumference, smoking status (never/former/present), smoking duration, smoking intensity, time since cessation, education, and physical activity (sport yes/no and cycling yes/no).

${ }^{3}$ Cut points for dietary vitamin C: $\leq 65.19 \mathrm{mg} ; \leq 91.77 \mathrm{mg} ; \leq 127.75 \mathrm{mg}$; cut points for supplemental vitamin C: $0 \mathrm{mg} ;>0 \mathrm{mg}-\leq 39.96 \mathrm{mg} ; \leq 60.00$ $\mathrm{mg}$.

${ }^{4}$ Cut points for dietary folate: $\leq 254.96 \mu \mathrm{g} ; \leq 318.77 \mu \mathrm{g} ; \leq 395.80 \mu \mathrm{g}$; cut points for supplemental folate: $0 \mu \mathrm{g} ;>0 \mu \mathrm{g}-\leq 83.2 \mu \mathrm{g} ; \leq \mathrm{I} 0.0 \mu \mathrm{g}$.

${ }^{5}$ Cut points for dietary vitamin E: $\leq 6.51 \mathrm{mg} ; \leq 8.36 \mathrm{mg} ; \leq 10.60 \mathrm{mg}$; cut points for supplemental vitamin E: $0 \mathrm{mg} ;>0 \mathrm{mg}-\leq 6.66 \mathrm{mg} ; \leq 10 \mathrm{mg}$.

${ }^{6}$ Cut points for dietary beta-carotene: $\leq$ I317.07 $\mu \mathrm{g}$; $\leq 2480.90 \mu \mathrm{g} ; \leq 4797.69 \mu \mathrm{g}$; cut points for supplemental beta-carotene: $0 \mu \mathrm{g} ;>0-\leq$ I250.00 $\mu \mathrm{g}$; $\leq 5994.00 \mu \mathrm{g}$.
}

(never, former, current), alcohol intake (abstainers, $\leq 10$ $\mathrm{g} /$ day, $>10 \mathrm{~g} /$ day $)$ and BMI $(\leq 25,>25)$. There was a significant interaction between dietary folate and smoking status with an increased mortality risk among never smokers (IRR: 1.12, 95\% CI: 1.05-1.19) but not among former and current smokers. Also, the effect of dietary vitamin E was significantly modified by smoking status with a similar increased risk of mortality (IRR: 1.27, 95\% CI: 1.04-1.55) among never smokers but not among former and current smokers. Among current smokers, in fact, a significantly decreased risk was found (IRR: 0.79, 95\% CI: 0.69-0.91) (Table 3). When considering effect modification by alcohol intake, dietary vitamin $\mathrm{E}$ was associated with significantly decreased risk of death among those consuming above $10 \mathrm{~g}$ alcohol/day (IRR: 0.76, 95\% CI: 0.66-0.87) but not among those consuming less or no alcohol (Table 4). No significant interactions were found between micronutrient intake and BMI (results not shown).

We also evaluated effect modification by intake from opposite sources. Supplemental intake was categorised by dietary intake: two equally sized groups consuming below the recommended daily intake (RDI) and two equally sized groups consuming above the RDI for vitamins $\mathrm{C}$, E, and folate. For beta-carotene no categorisation on diet was conducted, as supplement use was very limited and could therefore not be considered in multiple groups. No beneficial effects of supplement consumption were seen, regardless of the dietary intake of the micronutrient in question. Furthermore, we evaluated if the effect of dietary micronutrients differed among users and non-users of the corresponding supplement. No significant differences were found (results not shown). 
Table 3. Incidence rate ratio for mortality associated with intake of vitamin $\mathrm{C}$, folate, vitamin $\mathrm{E}$, and beta-carotene

\begin{tabular}{|c|c|c|c|c|c|c|c|}
\hline & \multicolumn{2}{|c|}{$\begin{array}{c}\text { Never Smokers ( } 1,223 \text { cases / I8,350 } \\
\text { non-cases })\end{array}$} & \multicolumn{2}{|c|}{$\begin{array}{c}\text { Former smokers ( } 1,630 \text { cases/14, } 103 \\
\text { non-cases })\end{array}$} & \multicolumn{2}{|c|}{$\begin{array}{c}\text { Current Smokers (3,914 cases/16,233 } \\
\text { non-cases) }\end{array}$} & \multirow{2}{*}{$\begin{array}{c}P \text {-value from } \\
\text { adjusted analyse }\end{array}$} \\
\hline & Crude IRR' $95 \% \mathrm{Cl}$ & Adjusted IRR ${ }^{1,2} 95 \% \mathrm{Cl}$ & Crude IRR' $95 \% \mathrm{Cl}$ & Adjusted IRR ${ }^{1,2} 95 \% \mathrm{Cl}$ & Crude IRR' $95 \% \mathrm{Cl}$ & Adjusted IRR ${ }^{1,2} 95 \% \mathrm{Cl}$ & \\
\hline Vitamin C & $1.03(0.93-1.14)$ & I.II (I.00-I.24) & $0.96(0.87-1.05)$ & $1.06(0.96-1.17)$ & $0.90(0.85-0.96)$ & $1.03(0.96-1.10)$ & 0.37 \\
\hline \multicolumn{8}{|l|}{ Dietary intake } \\
\hline Supplemental intake & $1.01(0.98-1.04)$ & $1.01(0.98-1.03)$ & $0.99(0.97-1.01)$ & $0.99(0.97-1.02)$ & $1.00(0.99-1.02)$ & $1.01(0.99-1.02)$ & 0.54 \\
\hline \multicolumn{8}{|l|}{ Folate } \\
\hline Dietary intake & $\mathrm{I} .05(0.99-\mathrm{I} . \mathrm{II})$ & $1.12(1.05-1.19)$ & $0.97(0.92-1.01)$ & $1.03(0.97-1.09)$ & $0.95(0.92-0.98)$ & $0.99(0.95-1.03)$ & 0.0005 \\
\hline Supplemental intake & $1.02(1.01-1.04)$ & $1.02(1.01-1.03)$ & $1.01(0.99-1.03)$ & $1.01(0.99-1.03)$ & $1.02(0.99-1.05)$ & 1.01 (0.98-1.04) & 0.69 \\
\hline \multicolumn{8}{|l|}{ Vitamin $\mathrm{E}$} \\
\hline Dietary intake & $1.21(1.01-1.45)$ & $1.27(1.04-1.55)$ & $0.91(0.77-1.07)$ & $0.98(0.81-1.18)$ & $0.72(0.65-0.80)$ & $0.79(0.69-0.91)$ & $<.0001$ \\
\hline Supplemental intake & $1.00(0.99-1.01)$ & $1.00(0.99-1.01)$ & $1.01(1.00-1.01)$ & $1.01(1.00-1.02)$ & $1.00(0.99-1.01)$ & $1.00(0.99-1.01)$ & 0.26 \\
\hline \multicolumn{8}{|l|}{ Beta-carotene } \\
\hline Dietary intake & $0.95(0.90-1.01)$ & $0.97(0.92-1.03)$ & $0.97(0.92-1.02)$ & $1.01(0.96-1.06)$ & $0.88\left(\begin{array}{lll}0.84 & 0.92)\end{array}\right.$ & $0.97(0.93-1.01)$ & 0.36 \\
\hline Supplemental intake & $1.08(0.89-1.31)$ & $1.04(0.85-1.27)$ & $1.06(0.89-1.26)$ & $1.05(0.89-1.25)$ & $0.98(0.82-1.18)$ & $0.97(0.8 I-1.16)$ & 0.77 \\
\hline
\end{tabular}

Note: Stratified by smoking status.

I Per each additional $100 \mathrm{mg}$ vitamin C, $100 \mu \mathrm{g}$ folate, $10 \mathrm{mg}$ vitamin $\mathrm{E}$, or 5,000 $\mu \mathrm{g}$ beta-carotene.

${ }^{2}$ Adjusted for total intake of the three other micronutrients as well as dietary intake for the supplemental intake and supplemental intake for the dietary intake and further for alcohol intake, BMI, waist circumference, smoking duration, smoking intensity, time since cessation, education, and physical activity (sport yes/no and cycling yes/no). 
Table 4. Incidence rate ratio for mortality, associated with intake of vitamin C, folate, vitamin E, and beta-carotene

\begin{tabular}{|c|c|c|c|c|c|c|c|}
\hline & \multicolumn{2}{|c|}{ Abstainers ( 314 cases $/ 974$ non-cases) } & \multicolumn{2}{|c|}{$>0-\leq 10 \mathrm{~g} /$ day $(2,23 \mathrm{I}$ cases/18,040 non-cases $)$} & \multicolumn{2}{|c|}{$>10 \mathrm{~g} /$ day $(4,222$ cases $/ 29,672$ non-cases $)$} & \multirow[b]{2}{*}{$P$-value from adjusted analyses } \\
\hline & Crude IRR' $95 \% \mathrm{Cl}$ & Adjusted IRR ${ }^{1,2} 95 \% \mathrm{Cl}$ & Crude IRR' $95 \% \mathrm{Cl}$ & Adjusted IRR $1, .295 \% \mathrm{Cl}$ & Crude IRR' $95 \% \mathrm{Cl}$ & Adjusted IRR ${ }^{1,2} 95 \% \mathrm{Cl}$ & \\
\hline \multicolumn{8}{|l|}{ Vitamin C } \\
\hline Dietary intake & $0.96(0.82-1.13)$ & $1.04(0.89-1.22)$ & $0.91\left(\begin{array}{ll}0.84 & 0.98\end{array}\right)$ & $1.09(1.01 .00-1.18)$ & $0.81(0.76-0.86)$ & $1.00(0.94-1.08)$ & 0.24 \\
\hline Supplemental intake & $1.02(0.98-1.06)$ & $1.03(0.99-1.07)$ & $1.02(1.01-1.03)$ & $1.01(1.00-1.03)$ & $1.00(0.99-1.02)$ & $0.99(0.98-1.01)$ & 0.07 \\
\hline \multicolumn{8}{|l|}{ Folate } \\
\hline Dietary intake & $0.99(0.90-1.08)$ & $1.05(0.96-1.15)$ & $0.93(0.90-0.97)$ & $1.07(\mathrm{I} .0 \mathrm{I}-\mathrm{I} . \mathrm{I})$ & $0.93(0.91-0.96)$ & $1.04(1.00-1.08)$ & 0.60 \\
\hline Supplemental intake & $1.08(0.97-1.19)$ & $1.08(0.97-1.20)$ & $1.04(1.02-1.05)$ & $1.03(1.02-1.05)$ & $1.00(0.98-1.02)$ & $1.00(0.98-1.03)$ & 0.07 \\
\hline \multicolumn{8}{|l|}{ Vitamin E } \\
\hline Dietary intake & $\mathrm{I} .05(0.79-\mathrm{I} .4 \mathrm{I})$ & $0.97(0.7|-| .3 \mid)$ & $0.89(0.78-1.03)$ & $0.93(0.79-1.10)$ & $0.67(0.60-0.74)$ & $0.76(0.66-0.87)$ & 0.0325 \\
\hline Supplemental intake & $0.99(0.96-1.02)$ & $1.00(0.97-1.02)$ & $1.01(1.00-1.01)$ & $1.01(1.00-1.02)$ & $1.00(0.99-1.00)$ & $1.00(0.99-1.00)$ & 0.05 \\
\hline \multicolumn{8}{|l|}{ Beta-carotene } \\
\hline Dietary intake & $0.79(0.69-0.90)$ & $0.90(0.79-1.02)$ & $0.89(0.85-0.93)$ & $0.98(0.94-1.03)$ & $0.85(0.81-0.89)$ & $0.98(0.94-1.02)$ & 0.39 \\
\hline Supplemental intake & $0.85(0.47-1.55)$ & $0.96(0.55-1.68)$ & $1.02(0.86-1.2 I)$ & $1.01(0.85-1.22)$ & $1.05(0.9|-| .2 I)$ & $1.03(0.89-1.19)$ & 0.97 \\
\hline
\end{tabular}

Note: Stratified by alcohol intake.

' Per each additional $100 \mathrm{mg}$ vitamin C, $100 \mu \mathrm{g}$ folate, $10 \mathrm{mg}$ vitamin $\mathrm{E}$, or $5,000 \mu \mathrm{g}$ beta-carotene.

${ }^{2}$ Adjusted for total intake of the three other micronutrients as well as dietary intake for the supplemental intake and supplemental intake for the dietary intake and further for BMI, waist circumference, smoking status (never/former/present), smoking duration, smoking intensity, time since cessation, education, and physical activity (leisure time sport yes/no and cycling yes/no). 


\section{Discussion}

In this prospective Danish cohort study, supplemental folic acid was associated with an increased risk of death. None of the dietary micronutrients investigated were associated with overall mortality and neither was any other supplemental micronutrient. Effect modification was found for smoking and dietary folate, and vitamin E, and for alcohol and dietary vitamin $\mathrm{E}$, whereas no effect modification by BMI was found.

The strengths of the present study include a long follow-up time, allowing accumulation of a large number of cases. The prospective design eliminated the risk of recall bias. We had complete and valid identification of all deaths and comprehensive information on dietary and supplemental micronutrients. This made precise calculations of micronutrient intake with source possible, enabling us to mutually adjust dietary and supplemental consumption of each micronutrient. Comprehensive information was also available on potential confounders.

The estimation of dietary micronutrient intake may be imprecise due to the variation in micronutrient content in different foods, varying with climate, growth, and storage. Also, use of baseline micronutrient consumption as a proxy for consumption during the entire study period may not be accurate, especially so for supplement use. However, possible bias from these factors is expected to be non-differential and should lead to bias towards the null, if any.

This study was conducted in a population with a relatively high dietary micronutrient intake (Table 1). Dietary intake of vitamin $\mathrm{C}$ and folate in the cohort is above the RDI (37) for both sexes and vitamin E also for women. For beta-carotene no RDI exists. This suggests a population that is by no means deprived in micronutrient status. For poorly nourished populations, previous studies have suggested beneficial effects of micronutrient supplements in relation to mortality $(38-40)$, whereas randomised, controlled trials (RCTs) on micronutrient supplements and overall mortality in well-nourished adult populations have consistently not shown any effects of supplementation on risk of death (41-46), or even increased risk $(7,8)$, in line with our finding of no beneficial effects of adding micronutrient supplements to the diet.

In contrast, we found a significantly increased risk of death with supplemental folic acid. Folic acid from supplements have, in RCTs, been associated with an increased risk of colorectal adenomas (12), prostate cancer (11), lung cancer and mortality (47), and evidence is accumulating that folate may play a dual role in carcinogenesis with harmful effects among persons harbouring pre-neoplastic lesions (48). No general tendency towards beneficial or harmful effects of folic acid supplementation has been found in RCTs on cardiovascular disease $(13,44-46,49)$. However, the detrimental effect of supplemental folic acid could be explained by an increased cancer risk alone. In previous studies examining supplemental folic acid in relation to lung, colorectal, breast, and bladder cancer in the Diet, Cancer and Health cohort, we have, however, not found increased incidence of these (50-53). And when considering causespecific mortality in this study, information that was available for participants deceased up until December 31, 2008, we found no association with cancer (IRR: 1.01; 95\% CI: 0.99-1.04) or cardiovascular disease (IRR: 0.96; 95\% CI: 0.86-1.07), but an increased risk of endocrine, nutritional, and metabolic disorders (IRR: 1.05; 95\% CI: 1.03-1.07), diseases of the respiratory system (IRR: 1.04; 95\% CI: 1.01-1.07), and diseases of the digestive system: (IRR: 1.04; 95\% CI: 1.01-1.06). The primary source of supplemental folic acid in the Diet, Cancer and Health cohort is multivitamins, followed by vitamin B complexes, or single folic acid supplements, but we did not have comprehensive information regarding folic acid source, allowing consideration of different effects of the diverse supplements. Other vitamin Bs associated with folic acid in vitamin B complexes may therefore be the true active ingredient. Control for intake of vitamin $B_{1}$, $\mathrm{B}_{2}, \mathrm{~B}_{3}, \mathrm{~B}_{6}$, and $\mathrm{B}_{12}$ did however not materially alter the estimate (IRR: $1.02 ; 95 \%$ CI: 1.00-1.03), suggesting that these could not fully explain the harmful effect.

With regards to effect modification by lifestyle factors, dietary vitamin $\mathrm{E}$ was associated with a decreased mortality among current smokers and those with an alcohol intake above $10 \mathrm{~g} /$ day (Table 3 and 4), and dietary folate was associated with an increased mortality among never smokers only (Table 3 ). These findings could be due to limited statistical power in the sub-groups defined by never/former smoking or abstinence/low alcohol intake, as a number of cases in these groups is substantially lower. Apart from the group of abstainers, however, the number of cases should be high enough to show an association if one was present. It is, therefore, also possible that these findings are the result of multiple testing or that they are caused by current smokers who neglect to inform about their true smoking status, leading to differential misclassification of these participants. And as smokers will often also have a lower dietary micronutrient intake $(54,55)$, this will skew the association towards being harmful among never smokers and beneficial among smokers. We would, however, then expect to see a similar effect modification by vitamin $\mathrm{C}$ and betacarotene. Smoking and alcohol are also known to lower the bioavailability of micronutrients $(56,57)$ and if these do indeed have harmful effects in relation to mortality, it is possible that these are cushioned by current smoking or a high alcohol intake. Another explanation for the findings could also be that only current smokers and those with a high alcohol intake have an additional benefit of a healthy diet. A similar effect of vitamin $\mathrm{C}$ and 
beta-carotene should, however, be expected then. Further studies examining effect modification by these factors are required.

The results of this study suggest that supplements containing the four included micronutrients have no effect in relation to overall mortality in a population of well-nourished Danes. In contrast, the only overall effect seems to be a harmful effect of supplemental folate. This finding, however, needs further scrutinising, as it does not seem to be a strong and consistent finding across different strata in the study where conflicting results are seen.

In conclusion, the results of this prospective observational study in a cohort of middle-aged Danes indicate no beneficial effect of dietary micronutrient intake in relation to mortality, suggesting that if these play a role in health and survival, it may be minor and related to specific outcomes, not generating an effect that can be seen in relation to overall mortality in a generally wellnourished population. A significantly increased risk of death with supplemental folic acid was found, which is in line with studies finding increased cancer incidence of folic acid supplementation. Finally, effect modification by smoking and alcohol was suggested and needs further exploration.

\section{Conflict of interest and funding}

This work was supported by grants from The Danish Cancer Society.

\section{References}

1. Valko M, Izakovic M, Mazur M, Rhodes CJ, Telser J. Role of oxygen radicals in DNA damage and cancer incidence. Mol Cell Biochem 2004; 266: 37-56.

2. Halliwell B. Effect of diet on cancer development: is oxidative DNA damage a biomarker? Free Radic Biol Med 2002; 32: 968 74.

3. Maxwell S, Greig L. Anti-oxidants - a protective role in cardiovascular disease? Expert Opin Pharmacother 2001; 2: $1737-50$.

4. World Cancer Research Fund. Food, nutrition, physical activity and the prevention of cancer - a global perspective. Washington, DC: AICR; 2007.

5. Willcox BJ, Curb JD, Rodriguez BL. Antioxidants in cardiovascular health and disease: key lessons from epidemiologic studies. Am J Cardiol 2008; 101: 75D-86D.

6. Cherubini A, Vigna GB, Zuliani G, Ruggiero C, Senin U, Fellin $\mathrm{R}$. Role of antioxidants in atherosclerosis: epidemiological and clinical update. Curr Pharm Des 2005; 11: 2017-32.

7. Bjelakovic G, Nikolova D, Gluud L, Simonetti R, Gluud C. Antioxidant supplements for prevention of mortality in healthy participants and patients with various diseases. Cochrane Database Syst Rev 2008; 2: CD007176.

8. Bardia A, Tleyjeh IM, Cerhan JR, Sood AK, Limburg PJ, Erwin PJ, et al. Efficacy of antioxidant supplementation in reducing primary cancer incidence and mortality: systematic review and meta-analysis. Mayo Clin Proc 2008; 83: 23-34.
9. The alpha-tocopherol, beta-carotene lung cancer prevention study: design, methods, participant characteristics, and compliance. The ATBC Cancer Prevention Study Group. Ann Epidemiol 1994; 4: 1-10.

10. Omenn GS, Goodman GE, Thornquist MD, Balmes J, Cullen MR, Glass A, et al. Effects of a combination of beta carotene and vitamin $\mathrm{A}$ on lung cancer and cardiovascular disease. $\mathrm{N}$ Engl J Med 1996; 334: 1150-5.

11. Figueiredo JC, Grau MV, Haile RW, Sandler RS, Summers RW, Bresalier RS, et al. Folic acid and risk of prostate cancer: results from a randomized clinical trial. J Natl Cancer Inst 2009; 101: $432-5$.

12. Cole BF, Baron JA, Sandler RS, Haile RW, Ahnen DJ, Bresalier RS, et al. Folic acid for the prevention of colorectal adenomas: a randomized clinical trial. JAMA 2007; 297: 2351-9.

13. Bonaa KH, Njolstad I, Ueland PM, Schirmer H, Tverdal A, Steigen $\mathrm{T}$, et al. Homocysteine lowering and cardiovascular events after acute myocardial infarction. N Engl J Med 2006; 354: $1578-88$.

14. Flynn A, Hirvonen T, Mensink GB, Ocke MC, Serra-Majem L, Stos $\mathrm{K}$, et al. Intake of selected nutrients from foods, from fortification and from supplements in various European countries. Food Nutr Res 2009; 53.

15. Skeie G, Braaten T, Hjartaker A, Lentjes M, Amiano P, Jakszyn $\mathrm{P}$, et al. Use of dietary supplements in the European Prospective Investigation into Cancer and Nutrition Calibration Study. Eur J Clin Nutr 2009; 63: S226-38.

16. Rock CL. Multivitamin-multimineral supplements: who uses them? Am J Clin Nutr 2007; 85: 277S-9S.

17. Fairfield KM, Fletcher RH. Vitamins for chronic disease prevention in adults: scientific review. JAMA 2002; 287: 3116-26.

18. Lichtenstein AH, Russell RM. Essential nutrients: food or supplements? Where should the emphasis be? JAMA 2005; 294: 351-8.

19. Sauer J, Mason JB, Choi SW. Too much folate: a risk factor for cancer and cardiovascular disease? Curr Opin Clin Nutr Metab Care 2009; 12: 30-6.

20. Whitworth A. Micronutrients: to supplement, or not to supplement? J Natl Cancer Inst 2006; 98: 230-2.

21. Woodside JV, McCall D, McGartland C, Young IS. Micronutrients: dietary intake v. supplement use. Proc Nutr Soc 2005; 64: $543-$.

22. Prentice RL. Clinical trials and observational studies to assess the chronic disease benefits and risks of multivitamin-multimineral supplements. Am J Clin Nutr 2007; 85: 308S-13S.

23. Meyskens FL Jr, Szabo E. Diet and cancer: the disconnect between epidemiology and randomized clinical trials. Cancer Epidemiol Biomarkers Prev 2005; 14: 1366-9.

24. Martinez ME, Marshall JR, Giovannucci E. Diet and cancer prevention: the roles of observation and experimentation. Nat Rev Cancer 2008; 8: 694-703.

25. Greenwald P, Anderson D, Nelson SA, Taylor PR. Clinical trials of vitamin and mineral supplements for cancer prevention. Am J Clin Nutr 2007; 85: 314S-7S.

26. Brower V. An apple a day may be safer than vitamins. J Natl Cancer Inst 2008; 100: 770-2.

27. Byers T. Nutrition and lung cancer: lessons from the differing effects of foods and supplements. Am J Respir Crit Care Med 2008; 177: 470-1.

28. Tjonneland A, Olsen A, Boll K, Stripp C, Christensen J, Engholm G, et al. Study design, exposure variables, and socioeconomic determinants of participation in diet, cancer and health: a population-based prospective cohort study of 57,053 men and women in Denmark. Scand J Publ Health 2007; 35: $432-41$ 
29. Overvad K, Tjonneland A, Haraldsdottir J, Ewertz M, Jensen OM. Development of a semiquantitative food frequency questionnaire to assess food, energy and nutrient intake in Denmark. Int J Epidemiol 1991; 20: 900-5.

30. Tjonneland A, Overvad K, Haraldsdottir J, Bang S, Ewertz M, Jensen OM. Validation of a semiquantitative food frequency questionnaire developed in Denmark. Int J Epidemiol 1991; 20: 906-12.

31. Tjonneland A, Haraldsdottir J, Overvad K, Stripp C, Ewertz M, Jensen OM. Influence of individually estimated portion size data on the validity of a semiquantitative food frequency questionnaire. Int J Epidemiol 1992; 21: 770-7.

32. Haraldsdottir J, Tjonneland A, Overvad K. Validity of individual portion size estimates in a food frequency questionnaire. Int J Epidemiol 1994; 23: 786-96.

33. Lauritsen, J. FoodCalc. http://www.ibt.ku.dk/jesper/foodcalc [cited 17 December 2008].

34. Allison PD. Survival analysis using SAS. Cary, NC: SAS Institute; 1995.

35. Greenland S. Avoiding power loss associated with categorization and ordinal scores in dose-response and trend analysis. Epidemiology 1995; 6: 450-4.

36. Greenland S. Dose-response and trend analysis in epidemiology: alternatives to categorical analysis. Epidemiology 1995; 6: 356-65.

37. Nordisk Ministerråd. Nordic nutrition recommendations 2004. Integrating nutrition and physical activity (4th ed.). Copenhagen: Nordic Council of Ministers; 2004

38. Mark SD, Wang W, Fraumeni JF Jr, Li JY, Taylor PR, Wang GQ, et al. Do nutritional supplements lower the risk of stroke or hypertension? Epidemiology 1998; 9: 9-15.

39. Hercberg S, Galan P, Preziosi P, Bertrais S, Mennen L, Malvy $\mathrm{D}$, et al. The SU.VI.MAX Study: a randomized, placebocontrolled trial of the health effects of antioxidant vitamins and minerals. Arch Intern Med 2004; 164: 2335-42.

40. Qiao YL, Dawsey SM, Kamangar F, Fan JH, Abnet CC, Sun $\mathrm{XD}$, et al. Total and cancer mortality after supplementation with vitamins and minerals: follow-up of the Linxian General Population Nutrition Intervention Trial. J Natl Cancer Inst 2009; 101: 507-18.

41. Hennekens CH, Buring JE, Manson JE, Stampfer M, Rosner B, Cook NR, et al. Lack of effect of long-term supplementation with beta carotene on the incidence of malignant neoplasms and cardiovascular disease. N Engl J Med 1996; 334: 1145-9.

42. Lee IM, Cook NR, Gaziano JM, Gordon D, Ridker PM, Manson JE, et al. Vitamin E in the primary prevention of cardiovascular disease and cancer: the Women's Health Study: a randomized controlled trial. JAMA 2005; 294: 56-65.

43. Lonn E, Bosch J, Yusuf S, Sheridan P, Pogue J, Arnold JM, et al. Effects of long-term vitamin E supplementation on cardiovascular events and cancer: a randomized controlled trial. JAMA 2005; 293: 1338-47.

44. Albert CM, Cook NR, Gaziano JM, Zaharris E, MacFadyen J, Danielson E, et al. Effect of folic acid and B vitamins on risk of cardiovascular events and total mortality among women at high risk for cardiovascular disease: a randomized trial. JAMA 2008; 299: 2027-36.
45. Ebbing M, Bleie O, Ueland PM, Nordrehaug JE, Nilsen DW, Vollset SE, et al. Mortality and cardiovascular events in patients treated with homocysteine-lowering B vitamins after coronary angiography: a randomized controlled trial. JAMA 2008; 300: 795-804.

46. Armitage JM, Bowman L, Clarke RJ, Wallendszus K, Bulbulia R, Rahimi K, et al. Effects of homocysteine-lowering with folic acid plus vitamin $\mathrm{B} 12$ vs placebo on mortality and major morbidity in myocardial infarction survivors: a randomized trial. JAMA 2010; 303: 2486-94.

47. Ebbing M, Bonaa KH, Nygard O, Arnesen E, Ueland PM, Nordrehaug JE, et al. Cancer incidence and mortality after treatment with folic acid and vitamin B12. JAMA 2009; 302: 2119-26.

48. Kim YI. Folate: a magic bullet or a double edged sword for colorectal cancer prevention? Gut 2006; 55: 1387-9.

49. Heinz J, Kropf S, Domrose U, Westphal S, Borucki K, Luley C, et al. B vitamins and the risk of total mortality and cardiovascular disease in end-stage renal disease: results of a randomized controlled trial. Circulation 2010; 121: 1432-8.

50. Roswall N, Olsen A, Christensen J, Dragsted LO, Overvad K, Tjonneland A. Source-specific effects of micronutrients in lung cancer prevention. Lung Cancer 2010; 67: 275-81.

51. Roswall N, Olsen A, Christensen J, Dragsted LO, Overvad K, Tjonneland A. Micronutrient intake and risk of colon and rectal cancer in a Danish cohort. Cancer Epidemiol 2010; 34: 40-6.

52. Roswall N, Olsen A, Christensen J, Dragsted LO, Overvad K, Tjonneland A. Micronutrient intake and breast cancer characteristics among postmenopausal women. Eur J Cancer Prev 2010; 19: 360-5.

53. Roswall N, Olsen A, Christensen J, Dragsted LO, Overvad K, Tjonneland A. Micronutrient intake and risk of urothelial carcinoma in a prospective Danish cohort. Eur Urol 2009; 56: 764-70.

54. Birkett NJ. Intake of fruits and vegetables in smokers. Public Health Nutr 1999; 2: 217-22.

55. Ma J, Hampl JS, Betts NM. Antioxidant intakes and smoking status: data from the continuing survey of food intakes by individuals 1994-1996. Am J Clin Nutr 2000; 71: 774-80.

56. Alberg A. The influence of cigarette smoking on circulating concentrations of antioxidant micronutrients. Toxicology 2002; 180: 121-37.

57. van den BH, van der GM, Hendriks H. Influence of lifestyle on vitamin bioavailability. Int J Vitam Nutr Res 2001; 72: 53-9.

\footnotetext{
*Nina Roswall

Institute of Epidemiology, Danish Cancer Society

Strandboulevarden 49

DK-2100 Copenhagen Ø

Denmark

Tel: +45 (35) 2577 14

Fax: + 45 (25) 77 3I,

Email: roswall@cancer.dk
} 